\title{
The Journey Toward Lean Manufacturing: Applying The Kaizen Blitz Method To Improving Operations
}

Mary J. Gander, (E-mail: mgander@winona.edu), Winona State University Kimberlee Snyder, (E-mail: ksnyder@winona.edu), Winona State University

\begin{abstract}
The authors researched an interesting example of the application of the Kaizen Blitz method to improving operations in a clean-room plant located in a suburb of Minneapolis, MN, USA, which is part of a division of a large, international medical products manufacturing company. Heartlung devices used in open heart surgery are manufactured in the plant. Under pressure to reduce medical costs and having benchmark data from competitors, it was clear that operations involved in manufacturing the heart-lung devices had lead times that were too long, required far too mисh inventory, were too labor-intensive in spite of using several expensive automated procedures, and had comparatively low yield rates, resulting in far too much waste. The information and data gathered by the authors were organized into a case study that is suitable for teaching process improvement methods in a university course as well as for industry training. The case details the context in which the Kaizen Blitz method was used, how it was applied, documents before and after conditions with key performance statistics, as well as provides background information on the Kaizen Blitz method. Selected references and sources are also provided.
\end{abstract}

\section{Introduction}

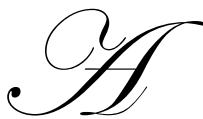

dvanced Medical Technologies, Inc. (Medtech) manufactures a variety of medical equipment and devices. It started in the Midwest and has grown steadily over the past 50 years. It has expanded in number of different products produced, market share, and number of plants. More recently, it has been engaged in a rather aggressive acquisition strategy and has expanded internationally. Medtech started out as a medical equipment repair company, not long after World War II. As the owners went to health facilities to repair equipment, they were increasingly asked to modify equipment, too. This opportunity lead to the development of biomedical products and manufacturing them, in fact, one of the first heart pace makers was made by Medtech. In 2001, their revenue was in excess of $\$ 5.5$ Billion, they were doing business in 120 countries with facilities worldwide, and they had approximately 25,000 employees (company website). Medtech's corporate headquarters remains in the Midwestern region of the USA.

Medtech manufactures medical devices for cardiac rhythm management, cardiac surgery, treatment of diabetes, neurological and spinal diseases, for treatment of vascular diseases, and ENT (ear, nose and throat) specialties. This paper deals with their Cardiac Surgery Division. Within that division are three main subdivisions: Heart Valves, Perfusion Systems, and Cardiac Surgery Technologies. We center on the Perfusion Systems Subdivision. It provides a comprehensive, innovative product line for patients undergoing cardiac surgery. Products include:

\footnotetext{
$>\quad$ Oxygenation systems

$>\quad$ Blood pumps

$>\quad$ Biocompatible surfaces

$>\quad$ Custom perfusion systems

$>\quad$ auto transfusion systems

$>\quad$ Blood diagnostics

$>\quad$ Cannulae
}

Readers with comments or questions are encouraged to contact the authors via email. 
Many of these products combine to create an individualized perfusion system that circulates and monitors a patient's blood and oxygen, in addition to regulating body temperature, during open-heart surgery. Three of the components of a profusion system, the Cardiovascular Reservoir, the Oxygenator, and the Pump, are manufactured in a clean room plant located in suburban Minneapolis, MN, USA. Each of these products is used once, then discarded. The first production line targeted for the lean transformation was the Cardiovascular Reservoir (CVR) line, which is described in some detail in this paper.

\title{
Medtech's Continuous Improvement and Lean Manufacturing Strategy
}

Medtech plant managers and corporate executives have investigated many of the well-known methods and philosophies related to quality, continuous improvement, and lean manufacturing, including: TQM, JIT, 6-Sigma, TOC, and SPC. Many employees have received and are receiving training in these methods. Until very recently, any tools and concepts from any of these methods which are found to hold value for improving any process in a plant, either on the manufacturing side or on the administrative support side, may be deployed by a plant to improve operations. At the time of this study (early fall, 2001 to April, 2002), it was up to individual plants to initiate and manage their own approach to improvement of operations, but there was a corporate-wide mandate to do so.

The motivation to increase efficiencies and reduce waste and cost in manufacturing profusion systems was generated by pressure from customers (medical facilities) to reduce costs, because of the great pressure on them from the public, from government, and from insurance companies to reduce their costs and prices. In addition, competition is increasingly tough as Medtech strives to hold onto and increase their market share, which is currently just under $50 \%$ of the perfusion systems market.

In early 2001, the responsibility for leading the efforts to improve operations at the CVR plant was assigned to the Manufacturing Engineering Manager, Tom Delaney. Tom was new in this position, coming to the plant with 14 years of experience in manufacturing engineering. Those reporting to him included manufacturing engineers, manufacturing technicians, maintenance technicians, and the machine shop and technicians. It was his unit's responsibility to support production's needs, develop and facilitate the implementation of continuous improvement activities, support the transfer of products from R \& D to production, and to keep manufacturing processes technologically current.

\section{The Journey to Lean Manufacturing on the CVR Line}

In addition to education and training in methods mentioned above, Tom elected to obtain concentrated training in Lean Manufacturing, a collection of concepts and methods promoted by Jim Womack and his Lean Enterprise Institute (www.lean.org). The following is an outline of the collection of methods and tools that were used on the CVR Line, as described by Delaney:

\author{
Value Stream Mapping \\ Optimized Flow \\ Materials \\ Information \\ The 5 S's \\ Sort, Shine, Systematize, Straighten, Standardize \\ Kanban \\ One-piece Flow and Pull Manufacturing \\ Standardized Work \\ Visual Workplace \\ Empowered Continuous Improvement Teams \\ Training \\ Equipment Management \\ Six Sigma Quality (3.4 defects per million opportunities)
}


Delaney defines "Lean Manufacturing" in the following way:

$>\quad$ An operating philosophy that examines the production system's "value stream" for identification and elimination of non-value-add actions (waste).

The "current state value stream" includes all actions, both those that add value and those that do not, that are currently used to bring a product from raw material to the customer.

According to Delaney, mapping the value stream of a production system should be the first step in the lean transformation. Value Stream Mapping (VSM) makes much that was invisible become visible. It focuses everyone's attention on the flow of production and illuminates crucial factors that are not visible unless mapped. VSM is not the same as flow charting a specific process. It is at a higher level and becomes a blueprint for lean implementation. It shows all the linkages between information flow and material flow, it illuminates how various parts of the production system relate to each other (or are fragmented or disconnected from each other), it focuses attention on inventory - how much there is and how and where in the system it accumulates, and it provides a common language and conceptual foundation for everyone in studying the production system.

Eliminating non-value-add elements in the production system is central to the lean transformation and therefore, everyone must learn more about waste. Waste does not add value, rather, it adds cost and time. Waste is not a root cause of problems, rather a symptom of problems hidden in the system. Thus, root causes of waste have to be determined. Often the "Why? Why? Why?" Inquiry and the fishbone diagram are useful tools for causal analysis. Waste is categorized into seven main types: Inventory (too much inventory - raw, WIP, and finished goods); Overproduction (manufacturing to schedule or forecast rather than to customer demand); Rework and Defects; Inspection (no quality at the source, inspection does not create quality); Product and Information Flow (any movement of material or information that does not add value); Waiting (wasted time); Motion (wasted motion); and Under Utilization of Talent. Delaney, in collaboration with his team and people from Production, determined that a useful approach to initiating the lean transformation was to begin with a Kaizen Blitz.

\section{What is a Kaizen Blitz?}

The word "Kaizen" comes from the Japanese language and may be translated as "sustained or continuous improvement" (www.gembakaizen.com). It focuses on eliminating waste in a process or system within an organization. A "Kaizen Blitz" or "Kaizen Event" as it is sometimes called, is a highly focused, short-term project designed to improve processes within a short timeframe, usually about two weeks. It centers on concentrated, quickly applied training, quick analysis and redesign and rearrangement of the elements of a production system. The Blitz process typically involves four phases. Phase one is the analysis of existing processes, brainstorming priorities and sequencing of the event and developing an estimation of the costs and savings to the process. A detailed workshop plan is developed in phase two. Here the team members determine support resources, and objectives of the Blitz event are hammered out. Phase three is the Kaizen Blitz workshop which is based on rapid cycles or bursts of education and training, followed by immediate application of the concepts and tools learned. The final phase involves sustaining the continuous improvement and training that were begun in the Blitz. Follow-up maintenance is crucial to maintaining the gains obtained from the Kaizen Blitz event. Some changes identified in the process may be too complex for the Blitz and will require effort to complete beyond the event period.

The intensity and urgency of a Kaizen Blitz tends to overcome much of the hesitation or resistance to change that slow implementation programs are usually faced with (www.strategosinc.com/kaizen_blitz.htm). The results are significant, clear, and quick, which in turn, generates enthusiasm and satisfaction. The Kaizen Blitz method typically is used at the beginning of Lean Manufacturing implementation as a part of the implementation, not instead of it, and it works best where there is a product or a small family of products that are amenable to this fastpaced improvement process.

\section{Kaizen Blitz on the CVR Production Line}

Delaney organized a core implementation team: two manufacturing engineers, one quality engineer, six people from production, and other support personnel from a variety of departments (e.g., materials management, the 
machine shop, purchasing, etc.), as well as key supplier representatives. Others were invited to meetings when their input was needed. The team identified and agreed on four main reasons for the Kaizen Event: (1) to improve flow (of both information and production); (2) to reduce cost; (3) to improve customer satisfaction (and reduce complaints - although, no CVR made by Medtech had ever failed in the field); and (4) to change the culture to one of continuous improvement.

As it turned out, the Kaizen Event spanned 5-6 weeks. Much was accomplished during week \#1. First, the Kaizen team participated in the well-known "Airplane Simulation" which graphically compares lean production to traditional production, thus teaching many important concepts with a hands-on example. Next the team experienced a series of concentrated training modules, each immediately followed by an application activity in which actual improvement work was done. These training and activity modules included the Five S's; Ergonomics and Safety; TAKT Time; Time-Observation; Line Balancing; Standard Work; Layout; Mock Layout; and finally, a problem solving and brainstorming session. The team prepared a formal presentation, summing up the week's activities and findings, which was presented to management.

Week \#2 was even more action-oriented. Mock and prototype fixtures, tables, and workstations were constructed as the team detailed their plan for implementation including how material would flow, how information would flow, how orders would flow, etc. At the end of the week, the team reviewed what they had done and planned for the next week.

During weeks \#3 and \#4 the team, in collaboration with others, including input from many shop floor workers, went through many iterations, incrementally improving on their work and information flow prototype process design, as they actually tested its functioning. During these weeks, they reviewed many of the concepts they were learning, reviewed data they had collected, and reviewed the system they were improving, talking to many people for input and ideas. They changed layouts, re-balanced, re-designed workstations, re-examined and defined standard work, ran the mock cell, and conducted time observations. TAKT time was calculated to be 56 seconds. Finally, at the end of the fourth week, they gave a presentation to management on what they had done and how it would work.

During week \# 5, the team and others installed and implemented the new workstations and the newly developed cell layout. Everyone was trained in detail on their new roles and how the cell would operate. Week \#6 was a continuation of this training and getting the improved system up and running. From that time on, they looked for and worked on additional improvement opportunities.

\section{Results}

For the purposes of this paper, data on performance indicators for the original production system are referred to as "pre-lean" and data on performance indicators after the 6-week Kaizen Event are referred to as "postlean." See Exhibits A and B for comparisons of pre and post-lean indicators. The plant still produced 840 units per day, but in pre-lean, it took three shifts, post-lean only 2 shifts. Whereas all production had been done in batches, post-lean it was done in single piece flow. Scrap and defect rates were significantly reduced, as were customer complaints. Cycle time and WIP reduction were highly significant (raw material inventory dropped, also). Pre-lean layout was linear, moving batches from work center to work center with a lot of WIP buffer in between and laying around. Even so, certain parts were often missing and had to be expedited. When a quality issue came up, defectives and causes were difficult and time consuming to find or track down, and with big batches and late inspection, many defects were created before the quality issue was even evident. In post-lean, quality issues were visible quickly and causes could be addressed quickly. With inventory reduced so much and so well organized, managing it was a different ball game entirely. Material and parts were readily available to workers (most at arm's height and with in comfortable reach), replenished as they was used. With one-piece flow, production problems were visible quickly and could be dealt with quickly. At first there was a tendency for workers to try to batch their work, but, through improvements in workstations, that became almost impossible-no place to put them. 


\begin{tabular}{|ll|}
\hline \multicolumn{2}{|c|}{ Exhibit A: Results of the Kaizen Event } \\
Pre-Lean State & Post-Lean State \\
$>$ 840 Units per day & $>840$ Unites per day \\
$>3$ Shifts & $>2$ Shifts \\
$>$ Batch & $>$ Single piece balanced flow with Kanban \\
$>$ High scrap and defect rates & $>$ Lowered scrap and defect rates \\
$>$ Long cycle time, too much WIP \& RIP & $>$ Reduced cycle time, WIP \& RIP \\
$>$ Products moved from work center to another & $>$ New way of thinking for operators \\
$>$ Work stations were buffered by WIP & $>$ U-shaped cell, workers cross-trained, \\
& parts and materials replenished as used \\
\hline
\end{tabular}

The changes, though quick with concentrated support training, were still not without pain to some workers. Also, getting some workers to provide input was sometimes difficult. With 27\% fewer employees needed post-lean, there had to be some re-assignments. Sometimes these were well accepted, in some cases, not. Also, there was some attrition. But, overall, resistance to change was not a highly significant issue among production employees.

\begin{tabular}{|llll|}
\hline & Exhibit B: Results of the Kaizen Event on CVR Production & \\
& Pre-Lean & Post-Lean & \% Change \\
> Production Operators & 44 People & 32 People & $-27 \%$ \\
> Number of Shifts & 3 & 2 & $-33 \%$ \\
> Square footage space used & 1550 & 950 & $-37 \%$ \\
> CVR mfg defect rate & 29,037 DPM & $13,899 \mathrm{DPM}$ & $-52 \%$ \\
> \# of work stations & 21 & 13 & $-38 \%$ \\
> Cycle Time & $423 \mathrm{~min}$. & $73 \mathrm{~min}$. & $-82 \%$ \\
> Average Scrap Dollars & $\$ 17,628$ & $\$ 6,193$ & $-65 \%$ \\
$>$ WIP & $\$ 1,573$ & $\$ 171$ & $-89 \%$ \\
$>$ RIP (Raw in Process) & $\$ 45.7$ & $\$ 13.7$ & $-71 \%$ \\
\hline
\end{tabular}

\section{Where Did They Go from There?}

Since Medtech did not yet have a corporate-wide, standard approach to lean transformation, from the beginning of the Kaizen Blitz, Delaney took on the responsibility of selling the approach used on the CVR Line, to management, keeping them informed, and coaching them on how to best react to the team's progress and activities. He fulfilled this important role very well. Management was well-rewarded for their support, as you can see by the results listed in Exhibit B. The Kaizen Event concluded in early fall of 2001, and the team submitted documentation of their achievements to the corporate-wide Medtech Excellence in Operations Award competition.

The CVR Line won the 2001 Medtech Excellence in Operations Award! Needless to say, management support for Delaney's leadership was strong as a result of all of these outcomes. Immediately following the Kaizen Event for CVR, Delaney began leading a similar event for production of the Oxygenator. That event was completed in January of 2002 with equally impressive results. At that time, Delaney was promoted to Operations Manager of a near-by Medtech plant that produces mechanical heart valves -- very important set of products but the traditional manufacturing process was in need of major over-haul. With Delaney now occupied at the other plant, how have the improvements on the CVR production system faired? As of mid-April, 2002, CVR production cycle time has dropped from a post-lean 73 minutes down to 31 minutes! This is a strong indication that continuous improvement, has indeed, taken root in the culture of the plant. Though this was the only indicator on which we obtained up-dated information, there are no doubt other areas revealing continuous improvement too, because cycle time is a good 
general indicator. Observation of Delaney's leadership reveals one key to success is the way he coaches and develops others to take over leadership roles. In addition, management is currently looking at developing a corporatewide approach to lean implementation based on the model use by the CVR Line.

\section{Conclusion}

The case of improving the CVR production system attests to the value of both the Kaizen Event method and the philosophy of lean manufacturing. A number of factors can be identified that contributed to the success of the lean implementation and Kaizen Event described in this study. Delaney's experience and initiative in learning as much as he could about continuous improvement and lean methods, as well as his leadership skills, are certainly important. The Kaizen Blitz methodology was used effectively, involving many employees and key suppliers in concentrated training with immediate, real application to improvement activities, use of Value Stream Mapping and actual testing of mock production system designs. Finally, real effort to sustain their excellent results and engage in the continued search for more opportunities for improvement. That is, building Kaizen into the culture.

Many of the methods and concepts in what is now called "lean manufacturing" were developed in Japan, many of them at Toyota, decades ago. It has taken Western industry a long time to understand and successfully implement this system of production, which is so different from traditional Western plant management, but cases of success and further development of the methods and ideas are accumulating and each one offers important lessons. $\mathbb{4} \mathbb{1}$

\section{References}

1. Hirano, Hiroyuki and Talbot, Bruce, 5 Pillars of the Visual Workplace: Sourcebook for 5S Implementation, Productivity Press, 1995, ISBN 153270471.

2. Imai, Masaaki, Gemba Kaizen, McGraw-Hill, 1997, ISBN 007034462.

3. $\quad$ Liker, Jeffrey, (Ed.), Becoming Lean, Productivity Press, 1998, ISBN 1563271737.

4. $\quad$ Womack, J. and Jones, D., Lean Thinking, Simon and Schuster, 1996, ISBN 0684810352.

5. Womack, J., Learning to See, Lean Enterprise Institute, Inc., 1999, ISBN 0966784308.

6. Womack, J., Jones, D., and Roos, D., The Machine that Changed the World, HarperCollins, 1991, ISBN 0060974176.

7. www.lean.org Website for the Lean Enterprise Institute (Jim Womack and colleagues). This sight has a bookstore from which a number of excellent sources may be ordered.

8. www.medtech.com (since the identity of the company is camouflaged, we cannot give the true company website address here.) 